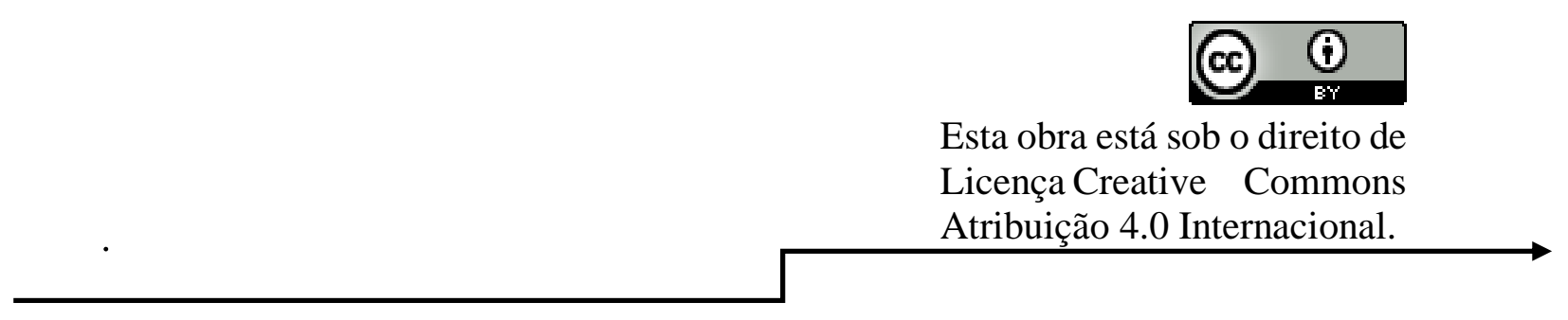

\title{
A FAMÍLIA E A ESCOLA NO DESENVOLVIMENTO DA APRENDIZAGEM
}

Andréia Santos Pereira ${ }^{1}$

\begin{abstract}
RESUMO
Este artigo tem como objetivo contribuir para o processo ensino-aprendizagem abordando sobre a importância da família na aprendizagem, pois a relação família-escola é de grande importância na construção da identidade, da autonomia, responsabilidade, conhecimento e exercício de cidadania para o sucesso no desenvolvimento intelectual, moral e na formação do indivíduo como um todo, visa mostrar a relação entre escola e a família, observando alguns aspectos importantes no que se refere ao papel e responsabilidades dessas duas instituições, e como as mesmas interagem na consecução de um objetivo comum: a aprendizagem das crianças. Dessa forma, tanto família quanto escola estão passando por profundas transformações e ambas precisam acompanhar tais mudanças de forma conjunta, facilitando o processo de aprendizagem e ajudando uns aos outros na busca de um objetivo comum, o de educar as crianças.
\end{abstract}

Palavras-Chaves: família, escola, aprendizagem.

\footnotetext{
${ }^{1}$ erlespereira@outlook.com
} 


\section{INTRODUÇÃO}

O presente trabalho pretende analisara importância da família e a escola no desenvolvimento da aprendizagem. Através de uma pesquisa bibliográfica analisar historicamente as transformações pelas quais estão passando tanto a instituição família como a instituição escola e como estas podem acompanhar as mudanças sem perder de vista o objetivo comum que é educar a criança e constatar a importância dessa parceria como contribuição para a melhoria da qualidade do ensino.

A família é o primeiro grupo social que possibilita o desenvolvimento de uma criança, pois é no meio familiar que o indivíduo encontra afeto, carinho, aprende sobre princípios, valores, respeito, cultura e ética. É primordial que os membros da família saibam preparar seus filhos para a educação formal, escolar. É advinda dos pais a responsabilidade pela educação dos filhos, por isso é importante a integração da família no ambiente escolar.

A instituição escolar é o segundo grupo social onde é oferecido todos os conceitos educacionais, culturais e formativos. No ambiente escolar ensinase também valores que são indispensáveis na vida das crianças, jovens ou adultos, preparando assim todos os estudantes para que no futuro possam se tornar cidadãos aptos para exercer seu papel na sociedade.

É de extrema importância a participação e colaboração da família no ambiente escolar, pois quando ocorre essa integração o professor participa efetivamente da vida do educando, conhecendo e percebendo melhor todas as qualidades $\mathrm{e}$ as dificuldades específicas do mesmo, facilitando assim que o educador elabore aulas mais significativas, possibilitando a promoção e o desenvolvimento no processo ensinoaprendizagem.

Ressalta-se neste artigo a importância de refletir o quanto a educação e os costumes transmitidos pela família influenciam não apenas no aprendizado, mas também na conduta e no comportamento apresentado pelo indivíduo em qualquer local, independente da presença familiar.

Contudo os resultados que se esperam alcançar da parceria família e escola é a integração, é uma parceria de verdade, pois unindo a instituição escola com a instituição família e todos os aspectos que envolvam a situação do aprender; como o amor, o respeito ao próximo, a colaboração e a troca, possibilita-se verdadeiramente uma educação de qualidade viabilizando de maneira positiva o desenvolvimento do aluno quanto ao processo de ensino aprendizagem, melhorando de maneira qualitativa e significativa sua situação escolar, quanto sua autoestima, integração social e familiar.

Enfim, a escola e a família têm a responsabilidade de educar os sujeitos que a elas pertencem, entretanto cada uma a sua maneira e com o seu objetivo que deve ser considerado e respeitado. O diálogo é a saída para que se estabeleçam relações de confiança e de cooperação entre essas duas instituições na busca do desenvolvimento da aprendizagem das crianças. 


\section{FAMÍLIA E ESCOLA}

É verdade que a modernidade trouxe uma série de mudanças, inclusive na família, mas tal realidade não isenta a instituição familiar de seu papel educador - primordial ao desenvolvimento e integração do filho à sociedade.

De acordo com Kaloustian (1988, p. 22) a família é:

[...] é o lugar indispensável para a garantia da sobrevivência e da proteção integral dos filhos e demais membros, independentemente do arranjo familiar ou da forma como vêm se estruturando. É a família que propicia os aportes afetivos e, sobretudo materiais necessários ao desenvolvimento e bem-estar dos seus componentes. Ela desempenha um papel decisivo na educação formal e informal, é em seu espaço que são absorvidos os valores éticos e humanitários, e onde se aprofundam os laços de solidariedade. É também em seu interior que se constroem as marcas entre as gerações e são observados valores culturais.

A educação familiar é um fator bastante importante na formação da personalidade da criança, desenvolvendo sua criticidade, ética e cidadania refletindo diretamente no processo escolar.

A sociedade tem passado por profundas mudanças nas últimas décadas, mudanças estas que tem afetado de forma fundamental a estrutura $\mathrm{e}$ equilíbrio das famílias. A escola também, ainda que de forma mais lenta e compassada, tem procurado se adaptar a essas mudanças, mas o que urge nos nossos dias é a interação entre ambas, promovendo uma maior eficiência na educação e ensino das crianças. Segundo

Osorio:

Costuma-se dizer que a família educa e a escola ensina, ou seja, à família cabe oferecer à criança e ao adolescente a pauta ética para a vida em sociedade e a escola instruí-lo, para que possam fazer frente às exigências competitivas do mundo na luta pela sobrevivência. (OSORIO, 1996, p.82).

A escola como detentora do conhecimento científico deve fornecer e promover nessa relação, todo seu cabedal de conhecimento de forma que esse esforço leve em consideração os aspectos particulares da posição social e cultural hora vigente, e que influenciam de forma decisiva o equilíbrio familiar.

Por sua vez as famílias, responsáveis pelo desenvolvimento social e psicológico de seus filhos, devem buscar a interação com a escola, promovendo, questionando, participando, sugerindo e interagindo de forma a fornecer subsídios que através de discussões e ampla comunicação com os educadores promovam as iniciativas que possibilitem o desenvolvimento do educando e vão de encontro às necessidades de cada indivíduo.

Uma ligação estreita e
continuada entre os professores
e os pais leva, pois, a muita
coisa mais que a uma
informação mutua: este
intercâmbio acaba resultando
em ajuda recíproca e,
frequentemente, em
aperfeiçoamento real dos
métodos. Ao aproximar a
escola da vida ou das
preocupações profissionais dos
pais, e ao proporcionar,
reciprocamente, aos pais um


interesse pelas coisas da escola, chega-se até mesmo a uma divisão de responsabilidades... (PIAGET, 1972 Apud JARDIM, 2006, p.50).

Necessário se faz uma abordagem individualizada dessas duas instituições para uma melhor compreensão de sua situação atual e como isso influencia a relação família escola, foco dessa abordagem.

Para Gokhale (1980), a família não é somente o berço da cultura e a base da sociedade futura, mas é também o centro da vida social. A educação bemsucedida da criança na família é que vai servir de apoio à sua criatividade e ao seu comportamento produtivo quando for adulto.

A família tem sido, é e será a influência mais poderosa para $o$ desenvolvimento da personalidade e do caráter das pessoas. Assim, pode-se dizer que as crianças precisam sentir que fazem parte de uma família.

Portanto podemos afirmar que nos dias atuais a escola não pode viver sem a família e a família não pode viver sem a escola, pois, é através da interação desse trabalho em conjunto, que tem como objetivo o desenvolvimento do bem-estar e da aprendizagem do educando, os quais contribuirão na formação integral do mesmo.

\section{RELAÇÃO ENTRE ESCOLA E FAMÍLIA}

A família, sendo à base de uma formação completa do indivíduo, tendo papel decisivo na formação de caráter, deve ter participação direta na educação das crianças. É fundamental que aconteça essa parceria entre escola e família, e que juntos possam alcançar o objetivo em comum, de formar cidadãos que saibam como viverem no mundo atual. Percebe-se que no atual momento em que vive a educação, a falta de envolvimento, participação, apoio e limites das famílias para com as crianças, torna difícil uma educação de qualidade. Freitas diz que:

Historicamente, até o século
XIX, havia uma separação das
tarefas da família e da escola: a
escola cuidada do que se
chamava "instrução", ou seja, a
transmissão dos
conhecimentos/conteúdo da
educação formal e a família se
dedicava à educação informal:
o que podia-se definir como o
ensinamento de valores,
atitudes e hábitos. No mundo
moderno, a educação passa
também a ser objeto de atenção
das famílias, que, apesar de ser
preocuparem com a qualidade
do ensino, transferem à escola
competências que deveriam ser
suas tão somente. Não veem a
escola como segunda etapa da
educação, mas criam nela toda
a expectativa de que será
responsável, a vida toda, pela
educação de seus filhos. E, em
muitas vezes, esquecem de
fazer sua parte (FREITAS,
2011 , p. 20).

A família é o primeiro grupo social que possibilita o desenvolvimento de uma criança, pois é no meio familiar que o indivíduo encontra afeto, carinho, aprende sobre princípios, valores, respeito, cultura e ética. É primordial que os membros da família saibam preparar seus filhos para a educação formal, escolar. 
Conforme Jardim, (2006) a relação escola e família vêm sendo muito discutida nos últimos tempos. A grande dúvida é saber os limites entre os deveres da família e os da escola. Como se sabe, não é a escola e sim a família que proporciona as primeiras experiências educacionais à criança.

\begin{abstract}
A família é o berço da formação de regras, princípios e valores, outras instituições assim como a escola, possuem também papel muito importante nesta formação moral, a escola se organizando de forma democrática, oportunizando uma vivência cidadã. Dessa forma, promovem o nascimento crescimento do respeito mútuo e o desenvolvimento da autonomia, ingrediente para formação moral. (SANDI, 2008, p. 34).
\end{abstract}

Definidos os papéis dos pais e professores, deve haver este respeito mútuo entre ambas as partes, mostrando suas opiniões e ouvindo sugestões, de forma respeitosa, para que assim a própria criança possa adquirir também esse valor e utilizar na sua vida cotidiana, respeitando o professor e seus próprios colegas dentro daescola e na sociedade.

Tal relação implica em colocar-se no lugar um do outro e não apenas enquanto troca de favores, mas “... a cooperação, em seu sentido mais prodigioso: o de supor afetos, permitir as escolhas, os desejos, o desenvolvimento moral, como construção dos próprios sujeitos, um trabalho constante com estruturas lógicas e as relações de confiança”. (TOGNETTA, 2002, apud JARDIM, 2006, p.20).
Tendo em vista o momento que vive a educação no país, stress de parte dos professores, despreparo de alguns, desvalorização do profissional, dificuldades de aprendizagem apresentada pelas crianças, violência, e levando em conta o quanto é importante a participação das famílias no processo de aprendizagem, é de grande interesse das escolas que esta interação ocorra, pode-se dizer que é papel da escola promover esta interação, garantindo uma troca de informação, orientando as famílias e mostrando o quanto é importante sua participação e presença na educação das crianças, pois quando as duas caminham juntas com o mesmo objetivo melhora a qualidade da educação os alunos aprendem com mais facilidade.

Baltazar \& Moretti (2003), acreditam que "a escola, através de seus professores ou diretores pode alertá-las e orientá-las, na tentativa de repensar sua conduta e agir de forma mais coerente com a realidade da criança”.

De acordo com Regis de Morais (1989), para que ocorra o aprendizado é preciso uma parceria entre o educador, uma participação efetiva das famílias na vida escolar da criança, "o ensina-te e ensinando, respeitando os limites de cada um e sua privacidade." O mundo, a sociedade, também educa, nós somos marcados por eles, e podemos aprender a todo o momento. É preciso a participação da família nesse aprendizado, a qual já se deu início a socialização.

\section{A FAMÍLIA EM PARCERIA COM A ESCOLA}


No momento em que escola e família conseguirem estabelecer uma parceria na maneira como irão promover a educação de seus alunos, muitos dos conflitos hoje apresentados em sala de aula, serão aos poucos superados. Todavia, para que isso possa aconteça é necessário que a família realmente participe da vida escolar de seus filhos. Que a família tenha comprometimento, envolvimento com a escola, gerando assim, na criança um sentimento de amor, fazendo sentir-se amparado e valorizado como ser humano. Nessa perspectiva, é oportuno novamente citar Içami Tiba, onde diz que:

Ensinar é transmitir o que você
sabe para quem quer saber,
portanto é dividir sua
sabedoria. Mas é uma estranha
divisão que não segue as leis
matemáticas, porque você
divide, mas não perde o que era
seu, pelo contrário, pode
ganhar o que nem lhe
pertencia. Ensinar faz o mestre
rever seus próprios
conhecimentos com
possibilidades de atualizá-los.
Os sentimentos de gratidão,
admiração e respeito do
aprendiz alimentam a alma do
mestre. Portanto, ensinar é
também trocar (TIBA, 1996).

Dessa forma, verifica-se que é necessário ressaltar que a tarefa de cuidar de maneira adequada de um ser em formação é extremamente difícil, pois requer que os educadores tenham capacidade de trabalhar com os conflitos gerados pela impulsão dos jovens em direção a satisfação rápida, às necessidades bi psíquico-sociais de cada momento.
A escola atual, de modo geral, apresenta maior disponibilidade em aceitar um relacionamento mais próximo com os pais. Todavia, o caminho percorrido para se chegar a tal interação foi um tanto difícil, em consequiência das transformações políticas, econômicas e sociais, das rupturas de paradigmas.

Os objetivos da escola, como também da família nos dias de hoje deverão procurar tornar a criança apta a assumir responsabilidades, tomar decisões, aprender qualquer ofício, desenvolver suas habilidades, como também orientar o educando na medida em que demonstre necessidade. A escola não deve apenas visar à construção do conhecimento, mas a formação de valores, atitudes e personalidade do aluno.

As escolas devem ser mais ativas e participativas, para despertar no aluno o desejo de aprender. E o apoio e a coesão familiar podem proporcionar as crianças uma estrutura equilibrada e sadia, para crescerem e tornarem-se cidadãos conscientes de seu papel na sociedade sendo capazes de interagir e intervir na realidade.

Nesse sentido, é importante que pais, professores, alunos dividam experiências, compreendam e trabalhem as questões envolvidas no seu dia-a-dia sem cair no julgamento "culpado e inocente", mas procurando compreender cada situação, uma vez que tudo o que se relaciona aos alunos tem a ver, de algum modo, com os pais e vice-versa, bem como tudo que se relaciona aos alunos tem a ver, sob algum ângulo, com a escola e vice-versa.

A escola e a família, cada qual com seus valores e objetivos específicos 
na educação de uma criança, constituem uma estrutura intrínseca, onde quanto mais diferentes são, mais necessitam uma da outra. Desse modo, cabe a toda sociedade, não apenas aos setores relacionados à educação, transformar o cotidiano da escola e da família, através de pequenas ações modificadoras, para que esta (a família) compreenda a importância dos objetivos traçados pela escola, assim como o seu lugar de responsável nesse processo (família).

\section{METODOLOGIA}

Trata-se de uma revisão de literatura tradicional, não sistemática, descritiva, de natureza qualitativa, com análise de conteúdo de livros e documentos adquiridos em bibliotecas físicas e virtuais.

\section{CONCLUSÃO}

Durante a pesquisa realizada constatou-se que a relação escola e família éimprescindíveis, pois a família como espaço de orientação, construção da identidade de um indivíduo deve promover juntamente com a escola uma parceria, a fim de contribuir no desenvolvimento da aprendizagem.

Um passo importante para a construção de uma aprendizagem significativa e integral é, a identificação da instituição família como uma instituição educadora, que caminhando de mãos dadas com a instituição escola, terá sempre o que transmitir e o que aprender. Sendo assim, é preciso que professores família e comunidade tenham claro que a escola precisa contar com o envolvimento e participação ativa de todos no processo de aprendizagem da criança.

A família é essencial para o desenvolvimento do indivíduo, independentemente de sua formação. É no meio familiar que o indivíduo tem seus primeiros contatos com o mundo externo, com a linguagem, com a aprendizagem e aprende os primeiros valores e hábitos.

A família e a escola precisam criar, através da educação, uma força para superar as suas dificuldades, construindo uma identidade própria e coletiva, atuando juntas como agentes facilitadores do desenvolvimento pleno do educando e que todos se sintam envolvidos no processo e queira junto com o professor alcançar o objetivo maior que é o compromisso com a educação.

É necessário que as famílias criem o hábito de participar da vida escolar das crianças, que perceba a importância de se relacionar com a escola na busca de um objetivo em comum, "educação de qualidade para as crianças". Por outro lado, a escola deve ser a responsável por criar meios de aproximação com as famílias e a comunidade, orientando e mostrando que educar não é papel exclusivo das escolas, é papel de todos. Todos juntos lutando por uma melhor educação

Escola e família devem estar juntas no trabalho pedagógico e social dos alunos, onde ambas terão a responsabilidade do desenvolvimento da criança no seu processo ensinoaprendizagem. Todavia, a falta da participação dos pais na vida escolar de seus filhos, pode causar problemas no ensino escolar como um todo. 
Portanto a sociedade urge por uma parceria de sucesso entre famílias e escolas, pois acreditamos que só assim poderemos, realmente, fazer uma educação de qualidade e que possa promover o bem estar de todos.

Conclui-se que a união destas duas instituições, escola e família, são imprescindíveis para a obtenção de resultados mais satisfatórios frente à formação de um cidadão mais íntegro e capaz de conviver em uma sociedade mais justa e feliz.

\section{REFERÊNCIAS BIBLIOGRÁFICAS}

FREITAS, Ivete Abbade. Família e

Escola: A Parceria Necessária na

Educação Infantil. Presidente

Prudente:São Paulo: Unoeste, 2006.

Baltazar, J. A.; Moretti, L. H. T. As

relações familiares, a escola, e sua

influência no desenvolvimento

infanto-juvenil e na aprendizagem.

São Paulo: Terra e cultura, ano $\mathrm{xx}, \mathrm{n}^{\circ}$ 39. 2003.

JARDIM, A. P. Relação entre Família

e Escola: Proposta de Ação no Processo

Ensino Aprendizagem. São Paulo:

Unoeste, 2006.

KALOUSTIAN, S. M. (org.) Família

Brasileira, a Base de Tudo. São Paulo:

Cortez; Brasília, DF: UNICEF, 1988.

MORAIS, Regis de. Cultura Brasileira

e Educação. Campinas, São Paulo,

Papirus,1989.

OSORIO, Luiz Carlos. Família Hoje.

Porto Alegre: Artes Médicas, 1996.
TIBA, Içami. Disciplina, limite na

medida certa. São Paulo: Gente, 1996.

GOKHALE, S. D. A Família

Desaparecerá? In Revista Debates

Sociais $\mathrm{n}^{\circ}$ 30, ano XVI. Rio de Janeiro, CBSSIS, 1980.

SANDI, Acedriana Vicente. Família berço da formação de regras, princípios e valores. Edição Especial Família. Curitiba: Positivo, ano 9, n.5, setembro/2008. 